\title{
Formação do Professor do Ensino Básico e a Avaliação Educacional*
}

\author{
HUGO DE LOS SANTOS ROJAS \\ Mestre em Educação - Psicologia da Educação, pela PUCSP \\ Professor de Matemática no Ensino Fundamental \\ hugorojo@colband.com.br
}

\begin{abstract}
Resumo
$\mathrm{O}$ artigo apresenta as conclusões de uma pesquisa acerca das dificuldades que os professores do ensino básico enfrentam no aprendizado de teorias e práticas sobre a avaliação que recorrentemente devem fazer de seus alunos, e como esses saberes vão se constituindo, tendo em vista não existir formação inicial para essa tarefa e a falta de clareza de como deve ser essa formação.

Palavras-chave: formação de professores, avaliação pedagógica, avaliação na sala de aula, modelos de avaliação.
\end{abstract}

\section{Resumen}

El artículo presenta las conclusiones de una investigación sobre las dificultades que los profesores de enseñanza primaria enfrentan en el aprendizaje de teorías y prácticas sobre la evaluación que habitualmente deben hacer de sus alumnos, y cómo esos saberes se constituyen, teniendo en cuenta que no existe una formación inicial para esta tarea y la falta de claridad sobre cómo debe ser esa formación.

Palabras-clave: formación de profesores, evaluación pedagógica, evaluación en el aula, modelos de evaluación.

\begin{abstract}
The article presents the conclusions of a research on difficulties that teachers of basic education face in learning the evaluation or assessment theories and techniques that they must recurrently apply to their pupils. It also deals with the possibilities of building such knowledge, as there is no pre-service training for this task nor a clear view of what this formation should be like.
\end{abstract}

Key-words: teacher education, pedagogical evaluation, classroom assessment, evaluation models.

\footnotetext{
* As reflexões apresentadas neste artigo têm por base a análise dos dados da dissertação de mestrado do autor (Rojas, 2007) e referem-se aos professores que trabalham no Ensino Fundamental. Agradeço à professora doutora Laurinda Ramalho de Almeida, que me orientou na realização da pesquisa de mestrado, e aos professores doutores Vera Maria Nigro de Souza Placo e Heraldo Marelim Vianna, pelas sugestões oferecidas na qualificação e na defesa do trabalho.
} 


\section{INTRODUÇÃO}

Na pesquisa, partimos do fato de que as concepções e as práticas dos professores do Ensino Básico, referentes à avaliação em sala de aula, têm sido objeto de crítica, há muitos anos, por parte de inúmeros pesquisadores educacionais. Ao serem observadas, porém, as condições que são oferecidas aos professores para a aprendizagem do complexo procedimento da avaliação, vê-se que sua formação inicial não a contempla, que há poucas oportunidades consistentes de formação continuada sobre a temática, que muitos pesquisadores que têm escrito sobre ela têm apontado mais seus problemas do que oferecido soluções realistas, e que as abordagens colocadas à disposição dos professores sobre o que deva ser a avaliação não são concordes entre si nem estão completamente estruturadas para a imediata aplicação em sala de aula.

A pesquisa teve por base a consideração de amplo panorama das abordagens avaliativas, presentes no discurso educacional brasileiro, norteamericano e europeu, bem como de pesquisas sobre a formação de professores, que tratam, entre outras situações, das dificuldades enfrentadas pelo professor para sua formação inicial ou continuada. Foi uma pesquisa qualitativa em que foram entrevistados 12 professores de escolas particulares da cidade de São Paulo, de diferentes áreas disciplinares, considerados pelos diretores ou coordenadores de suas escolas como muito envolvidos no processo de aprendizagem ou de reflexão sobre avaliação. Com base na análise das falas dos sujeitos e nas teorias consideradas, verificou-se que as dificuldades vividas quanto à avaliação a ser realizada em sala de aula são várias: falta de formação inicial para as questões avaliativas, formação inicial inadequada para o exercício da docência, dispersão de abordagens avaliativas para uso do professor, falta de material adequado para o estudo das diferentes abordagens, e questões ligadas à estruturação do trabalho docente número de alunos, o papel da instituição escolar, o grupo de professores em suas inter-relações.

Neste artigo, apresentaremos somente a análise dos dados da referida pesquisa, o que nos possibilitará fazer um contraponto entre o que se vivencia em relação à avaliação e o que se tem tentado implantar em diferentes ambientes escolares. 


\section{AVALIAÇÃO PEDAGÓGICA - PRIMEIRAS IMPRESSÕES}

No que diz respeito à avaliação realizada pelo professor em sala de aula, na sua forma mais conhecida, a base consiste em verificar se realizam as tarefas, aplicar provas e atribuir notas bimestrais ou trimestrais aos alunos, que serão usadas para a sua promoção ou retenção ao final do ano. Entender e praticar a avaliação nesses moldes tem a finalidade, apenas, de acumular informações para a secretaria escolar, sem que se faça realmente uma análise da situação de cada aluno, com base nos dados coletados, para uma retroação eficaz no que diz respeito às atividades de ensino, a fim de promover a aprendizagem.

Pelas condições que encontra no dia-a-dia da sala de aula e no ambiente das escolas em que trabalha, cada professor vai estabelecendo uma prática e constituindo um saber associado à avaliação, saber que se tem mostrado pouco disponível às mudanças requeridas há muito tempo e reforçadas pela Lei de Diretrizes e Bases da Educação, desde 1996. Também observamos que, no geral, a avaliação realizada na escola gera sempre certo mal-estar em todos os atores envolvidos: direção, professores, alunos e seus familiares.

Esse sentimento não está difundido apenas em escolas que realizam avaliações ditas tradicionais, como se poderia imaginar. Mesmo as que têm investido no aprimoramento da reflexão pedagógica entre seus professores e que têm conseguido maior participação das famílias no acompanhamento do desenvolvimento escolar dos alunos, podemos encontrar, de tempos em tempos, algum tipo de discordância importante entre os atores do processo educacional. São exemplos disso as reclamações a respeito de notas atribuídas a trabalhos e provas, a falta de apoio aos alunos que apresentam dificuldades de desenvolvimento e o modo de conseguir que se empenhem mais na tarefa de aprendizagem.

Isso ocorre, entre outros fatores, porque a avaliação educacional, em geral, e a avaliação que é feita em sala de aula, em particular, são procedimentos dependentes de valores e atitudes que demandam continuamente reflexão e ajustes. Muitas vezes, porém, os professores, em todos os níveis de ensino, bem como a equipe escolar, parecem não estar preparados para realizá-los. Alguns fatores que contribuem para esse problema são a formação inicial deficiente que receberam e as condições estruturais de trabalho, agravadas pela falta de oferta de cursos de formação continuada que suscitem novas condutas profissionais nos professores ou que possibilitem às equipes docentes novas abordagens para darem conta das inúmeras necessidades educativas de seus alunos, considerados individual ou coletivamente. 
Mas o problema da avaliação não diz respeito, apenas, ao mal-estar causado nos diferentes atores da atividade educacional. Para alguns pesquisadores, a partir do momento em que se iniciou a expansão da cobertura educacional para maiores contingentes populacionais, a avaliação se transformou, em muitos ambientes escolares, principalmente nas escolas públicas, em instrumento de exclusão social, porque inúmeros alunos abandonavam a escola depois de verem frustradas, em razão das várias reprovações, as possibilidades de ascenderem socialmente por meio da educação escolar.

Diante desses fatos, ainda que perdure há pelo menos três décadas, a questão premente, nos meios escolares e de pesquisa sobre avaliação educacional, diz respeito a como transformar a tarefa avaliativa de modo que não se contemple somente a necessidade burocrática da secretaria escolar - o lançamento de notas bimestrais nos boletins dos alunos. $\mathrm{O}$ objetivo é que essa tarefa assuma um papel articulador entre um ensino e uma aprendizagem significativos.

\section{PERCURSOS DA APRENDIZAGEM SOBRE A AVALIAÇÃO}

Ao responderem à pergunta sobre sua formação inicial em avaliação, nos cursos de graduação que fizeram, dos doze professores entrevistados, oito foram taxativos ao dizer que não estudaram coisa alguma sobre a temática avaliação ao longo desse período; dois afirmaram que não se lembravam de ter estudado o tema, não podendo, porém, afirmá-lo peremptoriamente; e os outros dois, em vez de responderem negativamente à questão, de forma direta, puseram em suspeição a eficácia da formação que receberam.

A essas lembranças de não haverem estudado aspectos teóricopráticos da avaliação, os professores acrescentam comentários a respeito da qualidade da graduação feita, pois têm a percepção de que tais cursos não se preocupavam com o que ocorria no dia-a-dia da sala de aula.

A formação inicial não se preocupou com o trabalho a ser realizado em sala. Nada se viu de avaliação. (P1-12.1)

Não aprendi nada de avaliação nos cursos da graduação. Os cursos de didática são horrorosos. (P2-22.1)

Na graduação, não aprendi nada que considere interessante. (P8-16.1)

Aprendi tudo o que precisava para a profissão fora do curso da graduação. (P420.1) 
A manifestação dos sujeitos sobre essa lacuna em sua formação inicial vem corroborar as constatações das pesquisas quanto à falta de projetos claros nas instituições que cuidam da formação do professor (Brzezinski, Garrido, 2002; Gatti, 2000, 2006). Ora, se não houve formação, pode-se hipotetizar que eles apoiaram-se nos exemplos de práticas avaliativas por que passaram ao longo de seu período escolar e universitário. Possivelmente, também, seu modelo inicial de ação, quanto à avaliação, deve ter sido o da intuição pragmática (De Ketele, 1993), em que o ato avaliativo é visto como algo intuitivo, sem que haja a necessidade de se preocupar com as seqüências de procedimentos próprias de muitas abordagens avaliativas (definição de objetivos, estabelecimento de critérios, modo de interpretar os resultados, entre outras), em que a prova e a nota são usadas, muitas vezes, como meios para conseguir do aluno uma participação disciplinada.

Os dados da pesquisa revelam também que, possivelmente, tenha sido a experiência profissional a responsável por dar aos sujeitos condições de adquirirem conhecimentos, melhorá-los e aprofundá-los.

Diante desse quadro inicial sobre os percursos da formação para a avaliação, podemos imaginar as dificuldades que todos esses professores, como tantos outros, enfrentaram para avaliar seus alunos. Como nosso objetivo é, no entanto, desvelar possíveis influências dos diferentes discursos avaliativos nas concepções dos sujeitos de nossa pesquisa, é preciso conhecer alguns aspectos desse fazer avaliativo. Por esse motivo, deixaremos outros fatores da formação (leituras, movimentos das instituições de ensino para fomentarem novas práticas, participação em palestras e em cursos etc.) para serem considerados depois da análise de como esses professores entendem a avaliação, apresentada no item a seguir.

\section{OS PROFESSORES E AS AVALIAÇÕES QUE REALIZAM}

Ao pensarmos nas relações que se estabelecem entre o professor, o aluno e o conhecimento a ser trabalhado por ambos, vemos que esse é o núcleo principal da atividade escolar. Quanto às atividades de avaliação, pensando em termos de stakeholders do processo, temos o professor e o aluno como os interessados imediatos nos resultados da avaliação, e, secundariamente, os familiares dos alunos, a secretaria da escola, a coordenação, a secretaria de educação responsável pela unidade de ensino, e a sociedade em geral.

Nesse processo, o professor tem um papel delicado, porque, ao mesmo tempo em que é um dos principais interessados, é quem demanda a 
avaliação que se vai realizar além de ser o responsável pela avaliação interna; em suma, é quem controla todo o processo, desde sua concepção até suas possíveis conseqüências. Ele apenas consegue sair dessa ambigüidade quando seus alunos são submetidos a outros tipos de avaliação, geralmente externos à escola, como o Saeb, o Enem, e o próprio vestibular. Nesses momentos, o professor vê que não somente seu trabalho está sendo avaliado, mas também os conhecimentos de seus alunos.

Que aspectos das práticas avaliativas dos sujeitos da pesquisa foram analisados? Ao longo de suas falas, nossos entrevistados expressaram o seguinte: a compreensão das finalidades da avaliação, sobre o que incide a avaliação que realizam, considerações a respeito dos instrumentos de coleta de informação, critérios para avaliar, a questão da devolutiva e como se trabalha a recuperação do aluno.

Tendo por base que a sua formação inicial para a avaliação foi precária, ou mesmo inexistente, que concepções sobre avaliação terão formado ao longo de sua prática profissional? Quais terão sido as linhas guias e de apoio para a superação dessa grande dificuldade que é a falta de formação para um procedimento complexo e tão importante como a avaliação? Na verdade, queremos saber que fatores têm influenciado as concepções avaliativas do professor, uma vez que acreditamos na aprendizagem ao longo da vida.

A interpretação que fizemos das falas dos sujeitos, acerca dos aspectos que possam tê-los influenciado, fez com que as agrupássemos da seguinte forma:

- a cobrança da sociedade sobre a escola;

- a forma de reagir dos alunos;

- o volume de trabalho;

- a visão dos colegas sobre o que deve ser o trabalho;

- o posicionamento da instituição (diretores e coordenadores).

Iniciemos nossa análise com o que nos parece significar "a cobrança da sociedade sobre a escola".

Algumas vezes, a geradora de pressão sobre as práticas docentes é a atitude dos pais, cobrando dos professores e da escola o trabalho com conteúdo tradicionais, quer seja porque não compreendem a nova forma de trabalhar dos professores - muitas vezes diferente da época que freqüentavam a escola, quando se faziam, por exemplo, intervenções nos erros ortográficos de modo enfático, quando se exigia a realização de longas séries de exercícios de caligrafia ou a memorização de determinados conteúdos etc. -, quer seja porque se preocupam com a formação dos filhos que, em tese, irão enfrentar o vestibular. Essa conduta dos pais é geradora 
de pressão porque coloca as práticas docentes em suspeição ou as desabona, tencionando sua modificação, o que causa, ao menos, desconforto nas relações que se estabelecem entre pais e escola, professores e coordenação, corpo docente e equipe de direção.

Os pais exigem provas escritas e pensam que avaliação é o conteúdo, cobram muito da escola informações e questionam muito as notas dos filhos. Para justificar essas notas, a escola tem de enviar boletins explicativos sobre comportamento etc. (P45.5)

O professor quer alçar vôos, mas a toda hora está sendo puxado. (P4-6.2)

Por isso, fica difícil para o professor abolir algumas práticas avaliativas com as quais é possível que não concorde mais, como a atribuição de notas aos trabalhos dos alunos ou em boletins, no final do período letivo, o que iria de encontro às expectativas dos pais sobre o que esperam da escola.

\section{A FORMA DE REAGIR DOS ALUNOS}

Em razão dessa pressão social por resultados, manifestada pelos pais, parece que os alunos estabelecem uma relação material e mercantil com a nota, o que dificulta, muitas vezes, o trabalho do professor em fazêlos entender que devem se preocupar com outros aspectos de suas produções e com o trabalho em seu próprio desenvolvimento.

Demanda, pois, grande esforço e experiência do professor saber estabelecer dinâmicas e entendimentos sobre o trabalho em sala de aula e com tudo o que está planejado para conseguir que os alunos comecem a deixar um pouco de lado seu apego à nota.

Se há um acordo didático, se o trabalho está acordado, não há problemas de entendimento das notas recebidas. Caso contrário, há reclamações e brigas, porque, também, o aluno quer nota, não quer ficar abaixo da média. (P10-9.5.b)

Os alunos, no começo, não têm a visão do que seja um processo, mas o professor, pela experiência, sabe se dá para chegar até o fim. (P11-21.10)

Há alunos que não imaginam o que é o envolvimento com a aprendizagem, pensando no desenvolvimento pessoal. Para esses, sua aprendizagem está na mão do outro, na responsabilidade do outro, não assumindo como algo seu. (P11-22.5) 
Mas essa vinculação do aluno à nota é apenas um dos fatores que influenciam o professor no que diz respeito à avaliação.

As formas como se dá a aprendizagem dos alunos e a possibilidade de o professor entender esse processo também têm impacto sobre a avaliação que ele realiza, pois tem de conhecer as dificuldades vivenciadas pelos alunos para poder interferir nelas ou mesmo modificar sua forma de trabalhar.

O processo de aprendizagem da criança coloca muitos desafios ao professor. (P25.4.a)

Há um limite nas tentativas do professor: a sala de aula com seus ritmos. (P105.1)

O professor deve ter o cuidado de não avançar sem considerar o rendimento de seus alunos. (P10-8.1)

\section{VOLUME DAS ATIVIDADES DOCENTES}

Se formos imaginar em que aspectos a forma de ser ou de reagir dos alunos e a cobrança da sociedade influenciam a avaliação realizada pelo professor, parece que a primeira é mais direta, mais perceptível, enquanto a segunda está mais difusa, na maior parte das vezes, para a maioria dos professores, haja vista que apenas os que lecionam nos últimos anos do ensino médio é que sentem mais a pressão, por exemplo, dos resultados dos alunos nos vestibulares. Essas duas influências sobre o proceder avaliativo do professor parecem estar relacionadas às preocupações que ele tem para realizar um trabalho melhor, não tendo relação, porém, com a profundidade desse fazer avaliativo, como é o caso da influência que o volume de trabalho diário e mesmo semanal possa ter.

A quantidade de trabalho pode influenciar, por exemplo, no alcance das atividades de avaliação e na sua qualidade, porque, como um dos professores afirma, o número de alunos pode inviabilizar a escolha de meios avaliativos mais complexos (P2-8.1), podendo prejudicar também a possibilidade de o professor conhecer melhor as reais dificuldades dos alunos.

Tem sido difícil encontrar momentos, situações, em que se possa estar próximo dos alunos, para conhecê-los e possibilitar melhores retornos para eles. Tem sido difícil não massificá-los. (P5-3.1) 
Fica muito custoso, para o professor, sair dos critérios vinculados aos objetivos e passar a considerar as evoluções que o aluno teve. Fazer isso tomaria muito tempo. (P12-8.3)

O volume de trabalho também pode dificultar as práticas investigativas do professor, pela demanda de tempo e pelo desgaste físico e mental que geram.

As funções dos professores na escola e suas atribuições não favorecem a prática investigativa, ou seja, uma prática voltada para a produção do aluno, o que os leva a preferirem provas de certo e errado, que são mais fáceis de corrigir. (P2-6.2 e 6.3)

O trabalho de uma avaliação do processo consome muito tempo e nem todo mundo tem esse tempo nem saúde para a empreitada. (P7-14.1)

\section{VISÃO DOS COLEGAS SOBRE O QUE DEVE SER O TRABALHO}

E o que dizer da influência ou mesmo interferência dos professores, do ponto-de-vista das representações, a respeito do trabalho de cada um? Algumas vezes, essas interferências são positivas, contribuindo para a criação de um espaço de reflexão ou para ajudar a assentar as bases do projeto comum do grupo:

As discussões entre professores sobre como andam os alunos, como é o trabalho, o que se deseja do trabalho coletivo e como se encaminham coletivamente as questões colocadas pelos professores são balizas para o que se deve ou se pode fazer. (P1-9.4)

No entanto, em ambientes onde os professores estão em diferentes estágios de desenvolvimento profissional ou nos quais não há, realmente, uma comunidade com projeto comum, as interferências dos colegas podem causar desconforto e até dificultar mudanças:

A dificuldade de tornar interessante e prazeroso os meios advém de um apego ao academicismo [...], da não concordância entre professores [...]. (P4-5.5)

Nos conselhos, há grandes questionamentos sobre este meu trabalho, porque ele é muito detalhado e detalhista. E com minhas fichas dou conta da vida do aluno. Parece cruel com os colegas, que também trabalham muito. (P2-20.5)

[...] E esse trabalho causa muita briga. (P2-13.1) 
Quanto ao posicionamento institucional, quer seja dos coordenadores ou diretores, quer pela representação difusa que se costuma fazer da "instituição", podemos ver que há divergências no posicionamento e na interferência das diferentes escolas de nossos sujeitos.

\section{O PAPEL DA INSTITUIÇÃO}

A escola de P1 exige aplicação de provas, mas dá liberdade de decisão sobre notas ou conceitos, tipos de instrumentos a serem utilizados e sobre a periodicidade da realização de provas, ainda que tenha fixado provas trimestrais.

A escola de P11 é da mesma rede de escolas de P1, mas possuem grupos dirigentes distintos, e estão localizadas em bairros diferentes. Isso faz com que haja uma diferenciação na prática, ainda que procurem seguir um ideário comum. Nessa escola, também se exige nota no final de cada período letivo e dá-se liberdade para que a discussão entre os professores leve à orientação das práticas.

Já a escola de P4 não tem clareza sobre o que quer. Segundo ele,

A escola sofre de uma esquizofrenia: exige diversificação do trabalho, mas cobra muito se a programação propedêutica está sendo cumprida. O professor tem de inovar e fazer o máximo, mas não pode se esquecer do cumprimento do programa. (P4-5.7)

Essa escola, ainda que tenha sido bem-sucedida na estruturação do currículo, desde o jardim até o terceiro ano do ensino médio, fazendo com que os professores tenham conhecimento de quais conteúdos devem ser trabalhados para que haja coerência em todo o trabalho e o abarcamento de todo o conteúdo disciplinar, não está presente como instituição, uma vez que não consegue mostrar com clareza suas idéias mestras, se é que existem realmente.

Não há orientadora que oriente nem ajude a limar as diferenças. As reuniões são burocráticas, em que se colocam as posições, mas não se dialoga. Há pouca noção de grupo; as concordâncias e discordâncias são veladas. (P4-17.1)

A escola de P2, P9 e P12 parece ter uma noção mais clara do que é ser uma instituição, pois concretizou seu ideário:

A escola tem uma perspectiva socioconstrutivista e faz, na prática, o que fala. (P221.1)

[...] Na escola, existe um trabalho de orientação, de parceria. (P2-23.3) 
A escola tem uma linha sempre esclarecida por direção e coordenação presentes. (P12-30.2)

E para que seu ideário acerca da formação dos alunos pudesse ser posto em prática decidiu estabelecer um currículo menos extenso do que a maioria das escolas, para possibilitar mudanças na maneira de se trabalhar com os conteúdos.

Já a escola de P3, P7 e P8 também dá liberdade para o professor escolher entre realizar várias provas comuns no período letivo ou aplicar uma única prova operatória ${ }^{1}$. Entretanto, no entender do professor P7, as discussões promovidas pela escola sobre avaliação são ainda formais, com muito discurso e pouca prática, apesar do empenho da coordenação.

Uma vez analisados os fatores que influenciam a avaliação que realizam, segundo as falas dos sujeitos, parece-nos importante descortinar um pouco mais suas práticas, procurando identificar a vinculação com algum modelo avaliativo específico. Não podemos nos esquecer, no entanto, de que analisamos as falas dos sujeitos em relação às práticas, uma vez que não era objetivo da pesquisa fazer observações a respeito dessas práticas.

\section{FINALIDADES DA AVALIAÇÃO}

No quadro a seguir temos a síntese das falas dos sujeitos a respeito das finalidades da avaliação.

\begin{tabular}{|c|c|}
\hline Finalidades associadas ao professor & Finalidades associadas ao aluno \\
\hline $\begin{array}{ll}\text { - } & \text { ver o que foi assimilado ou o que falta (P3, P6) } \\
\text { - } & \text { ver o resultado do trabalho desenvolvido (P8) } \\
\text { - } & \text { dimensionar o próprio trabalho (P7) } \\
\text { - } & \text { saber o que aconteceu para encaminhar próximos } \\
& \text { trabalhos (P3, P6, P8, P12) } \\
\text { - } & \text { verificar se as estratégias são boas para a } \\
& \text { aprendizagem dos alunos (P5) } \\
\text { - } & \text { ver o que deve ser retomado (P3, P8) } \\
\text { - } & \text { repensar o ensino ou correção de rumos (P2, P9, } \\
& \text { P11) } \\
\text { - } & \text { oferecer elementos para mexer no percurso de } \\
& \text { desenvolvimento (P6) } \\
\text { - } & \text { ajudar o aluno (P12) } \\
\text { - não é dizer que o aluno é A, B, C ou D (P2) } \\
\text { - } \quad \text { pressionar os alunos, como se fosse uma arma (P6) }\end{array}$ & $\begin{array}{l}\text { - fazer que o aluno se veja em seu } \\
\text { desenvolvimento (P2, P5) } \\
\text { - indicar ao aluno o que sabe, o que não sabe e o } \\
\text { que precisa fazer (P2, P5) } \\
\text { - indicar para o aluno a relação entre seu } \\
\text { desempenho e como vem trabalhando (P5) } \\
\text { - indicar avanços havidos e dificulda- des que } \\
\text { se podem enfrentar (P5, P8) } \\
\text { - o aluno ter controle sobre o próprio processo } \\
\text { (P6) }\end{array}$ \\
\hline
\end{tabular}

1 Ver, a esse respeito, Ronca e Terzi (1991). 
Nota-se que as finalidades podem ser divididas em dois grupos: as que estão relacionadas à reflexão e à ação do próprio professor, com inúmeros subaspectos, e as que se referem aos possíveis usos pelos alunos.

Quanto às finalidades associadas ao professor, percebemos que há desde a preocupação tradicional de saber o que foi assimilado pelo aluno, e mesmo a ação tão renegada por muitos pesquisadores de pressionar o aluno para controlar a indisciplina, até a de repensar o ensino.

"Ver o que foi assimilado" e "ver o resultado do trabalho desenvolvido" são as mais antigas preocupações dos professores em relação às suas práticas profissionais. Muito facilmente, ambas são vinculadas ao paradigma da intuição pragmática dos professores. É interessante perceber que apenas três professores manifestaram em suas falas essas preocupações. O que isso indica? Que a tendência entre os outros sujeitos da pesquisa, ou nas escolas em que trabalham, é não se preocupar com o resultado do trabalho realizado com os alunos e acreditar que há outros aspectos mais importantes que devem ser considerados? $\mathrm{Ou}$ será apenas falta de ênfase em algo tão corriqueiro e, portanto, hipotético?

São os conteúdos de aprendizagem apresentados por Zabala (1998) e Coll et al. $(1997,1998)$, porém, os que a sociedade considera importantes que as novas gerações assimilem. Vê-se que essas duas finalidades têm, sim, cabimento nas práticas avaliativas dos professores, não devendo ser descartadas com facilidade, em favor de qualquer outra finalidade. Nesse sentido, é claro que precisam ser ressignificadas, abandonando a cobrança simples de quaisquer conteúdos, apenas por terem sido apresentados aos alunos, prática já suficientemente criticada na literatura educacional.

Já a finalidade "dimensionar o próprio trabalho" parece indicar uma preocupação com o planejamento do trabalho e as próprias metas profissionais. Assim, poderia até ser considerada um objeto de avaliação pelo professor.

As seguintes finalidades: "saber o que aconteceu para encaminhar próximos trabalhos", "verificar se as estratégias são boas para a aprendizagem dos alunos", "ver o que deve ser retomado", "repensar o ensino ou correção de rumos", e "oferecer elementos para mexer no percurso de desenvolvimento" são muito importantes, se o que se quer é um trabalho eficaz para atingir as metas propostas para a educação. Todas elas podem ser encontradas nas preocupações dos docentes a partir da segunda geração avaliativa - a geração da descrição -, tal como apresentada por Guba e Lincoln (1989); contudo, parecem estar bastante ligadas às estratégias dos paradigmas da pedagogia da mestria e da avaliação formativa em um ensino diferenciado, porque neles é muito forte a preocupação com as estratégias de ensino para dar conta das 
necessidades dos alunos, uma vez que, se não há a preocupação com a retomada e o repensar de rumos, não há como aplicar os princípios da avaliação formativa.

Por fim, a finalidade "ajudar o aluno" é muito geral, e se concretiza adequadamente, em verdade, nas outras finalidades apresentadas e naquelas que se referem especificamente ao aluno. Já a finalidade negativa "não é dizer que o aluno é $\mathrm{A}, \mathrm{B}, \mathrm{C}$ ou D" parece enfatizar com clareza que é necessário problematizar a associação imediata que o senso comum faz entre avaliação-prova-nota. Desse modo, vê-se que há muito por fazer no terreno da avaliação, uma vez que a própria administração sustenta essa visão, ou melhor, parte dela, porque a burocracia escolar até admite avaliações sem provas, mas não concebe a inexistência de notas.

Quanto às finalidades associadas aos alunos, vemos que em todas a preocupação é que o aluno esteja envolvido com o próprio desenvolvimento, que não assuma uma posição passiva diante das ações do professor, mas que haja um comprometimento dele em todo o processo. Chama a atenção, contudo, o fato de que apenas uma manifestação - "o aluno ter controle sobre o próprio processo" - esteja definida como preocupação do aluno e não do professor, porque todas as outras indicam atitudes do professor.

Essas preocupações, que poderíamos associar à intenção de dar voz e vez aos alunos no processo de seu desenvolvimento escolar, estão de acordo tanto com abordagens da quarta geração avaliativa (Guba, Lincoln, 1989) quanto com as propostas que se baseiam em uma avaliação formativa como base do trabalho avaliativo. A escola inglesa enfatiza como é importante os alunos terem capacidade de avaliar a si próprios e o que devem fazer para melhorar, e que não só os professores, mas também os alunos devem estar envolvidos com a reflexão e revisão dos dados da avaliação (Black, Wiliam, 1998).

\section{SOBRE O QUE INCIDE A AVALIAÇÃO}

Muitos são os meios que os professores utilizam para avaliar os alunos: freqüência, lição de casa, envolvimento em sala etc. Tendo em vista que a maior parte das finalidades da avaliação percebidas nos discursos está voltada para a identificação do que precisa ser feito para ajudar o aluno em seu desenvolvimento, ou mesmo o que necessita ser retrabalhado pelos professores, justificam-se suas preocupações com a base, tanto em termos de conhecimentos prévios dos alunos como de comportamentos associados ao estudo. 
Há algumas colocações apresentadas pelos professores que são difíceis de concretizar, tendo em vista a sua operacionalização:

O professor deve acompanhar o envolvimento do aluno em sala. (P6-3.1)

Seria bom avaliar interesse, dedicação e vontade do aluno. (P7-3.6)

Parece não ser possível avaliar atitudes, porque, em verdade, não as ensinamos. A questão dos comportamentos precisa mais de compreensão do que de avaliação. (P12-12.2.b)

Nesses depoimentos, fala-se de uma preocupação geral do professor para que tudo corra bem, não havendo necessidade de recorrer a nenhuma estratégia específica de avaliação sistemática. Os professores P6, P7 e P12 parecem estar se referindo às dificuldades de se realizar avaliação de atitudes, ainda que, para eles, não fique explícito o conceito dessa dimensão.

Os conhecimentos dos alunos são avaliados em termos de qualidade e extensão, com base em suas produções - lições de casa, trabalhos e provas. No entanto, entende-se que a avaliação não é só de produto, mas também de processo.

\section{CONSIDERAÇÕES ACERCA DOS INSTRUMENTOS DE COLETA DE INFORMAÇÕES}

Quanto aos instrumentos de coleta de informação, não só as provas são utilizadas, mas também são feitas observações em sala - em folhas de registros -, redações, exercícios em aula, trabalhos - individuais e em grupo -, oficinas, lições de casa, análise do caderno do aluno, porque $a$ prova, apesar de instrumento formal, não é suficiente (P8-1.2.a).

Com relação à prova, há clareza sobre suas possibilidades e limitações:

Às vezes, as provas são quase cópia do que se trabalhou. (P4-11.2)

As provas rapidamente confeccionadas não dão um bom retrato do aluno. (P822.2)

A forma como se ensina deve interferir na forma como se avalia; assim, não tem sentido copiar provas de outros professores, porque não se trabalharam as atividades que estão na origem dessa prova nem se atentou para a forma como os alunos foram trabalhados. (P12-18.1) 
De modo geral, há a percepção de que para se exigir é necessário diversificar o material a ser apresentado aos alunos, mesmo sabendo que a grande quantidade de instrumentos não garante a qualidade da informação obtida. E, para se trabalhar a diversidade de conteúdos - factuais, conceituais, procedimentais e atitudinais -, outros meios diferentes das provas devem ser utilizados.

Vejamos o que pensam alguns professores a respeito dos critérios de correção:

É importante que os alunos saibam os critérios que devem estar disponiveis, porque, mesmo com dificuldades, eles podem retrabalhar suas produções, entendendo-as melhor. (P12-17.5)

Critérios de avaliação são passíveis de determinação conjunta aluno-professor. (P1-5.8)

O aluno deve ajudar no estabelecimento dos critérios [...]. (P6-5.6)

Contudo, o problema não é apenas de explicitação dos critérios, mas de compreender a sua utilização nas diferentes situações escolares. Assim, é necessário discutir com os alunos o seu estabelecimento e como se aplicam esses critérios, para que se apropriem dos níveis de exigência do professor. É justamente essa apropriação das formas de avaliar de seu professor que pode levar o aluno a compreender o que é o trabalho escolar e a qualidade que devem atingir em suas produções, tal como nos diz Wiliam (1998) na linha da avaliação formativa para a aprendizagem.

Essa preocupação com critérios de correção e com sua apropriação pelos alunos mostra que os sujeitos da pesquisa puderam refletir sobre a importância desse proceder, uma vez que, contrariamente ao que manifestam, é comum notar que muitos deles, quando muito, apresentam a seus alunos um arremedo de critérios, ao colocarem na lousa quanto valeu cada questão e ao comentarem em voz alta o que foi considerado como certo ou errado, muitas vezes pela apresentação da resposta correta.

Ou seja, essa preocupação dos professores está muito próxima à dos teóricos da avaliação formativa, para os quais é muito importante que os alunos compreendam todos os passos da avaliação, uma vez que ela tem como finalidade ajudá-los a corrigir seus percursos e a consolidar as aprendizagens que estão realizando. 


\section{DEVOLUTIVA - DIÁLOGO - INTERLOCUÇÃO}

É na perspectiva da avaliação formativa que fica mais evidente perceber que os sujeitos estão fazendo uso de uma concepção bastante avançada sobre avaliação. Estamos falando da devolutiva que os professores fazem para os alunos, quando realizam a análise de suas diferentes produções.

Identificamos que os diversos discursos avaliativos apresentam, grosso modo, como finalidade o melhoramento daquilo que está sendo avaliado. Entretanto, tornar isso uma realidade na escola tem sido uma tarefa muito difícil. As práticas escolares mais tradicionais sempre estiveram muito atreladas a uma prática pedagógica baseada na repetição do seguinte ciclo: apresentação dos conteúdos, exercitação, realização de uma prova, entrega das notas, cobrança por melhores resultados (com louvação aos "bons" e reprimendas aos "maus" alunos), apresentação de novo conteúdos etc.

Essa prática, apesar de vilipendiada por muitos, funciona em ambientes onde os estudantes mantêm alto envolvimento acadêmico - não importa se por pressões externas ou por disposição própria - porque, muitas vezes, há famílias que exigem resultados de seus filhos e têm condições de acompanhar a sua aprendizagem. No entanto, em ambientes pouco exigentes, ou naqueles em que fatores impedem o desenvolvimento (violência social, carências afetivas, alimentares e culturais, ambiente familiar desestruturado etc.), essa prática pedagógica apresenta poucos resultados acadêmicos.

Entretanto, mesmo considerando os ambientes em que essas práticas funcionam, o que as pesquisas sobre avaliação formativa vêm mostrando é que um procedimento avaliativo complexo, como é o da avaliação da aprendizagem (Black, Wiliam, 1998), bem aplicado, pode ajudar a elevar o rendimento dos alunos - mesmo daqueles que já têm rendimentos altos -, melhorando sua capacidade de compreensão e de execução de tarefas. Duas das características principais desse tipo de avaliação são a disponibilização de feedback efetivo para os alunos e o envolvimento ativo com sua própria aprendizagem.

Ora, é justamente isso que os sujeitos da pesquisa têm tentado em relação a suas avaliações.

Alunos ficam perdidos ao receberem o resultado da avaliação. (P6-22.1)

Dão importância igual a tudo, é importante ter sempre um comentário, porque ele ajuda a dar sentido ao que se faz e também direciona o olhar. (P12-2.6.a) 
É de pouco valor para o aluno receber provas com certo, meio certo e errado. Há que se cuidar da comunicação dos resultados. (P5-1.20)

O importante é indicar os erros para o aluno refazer o percurso. (P1-7.4)

Esse diálogo, essa interlocução que se estabelece entre professores e alunos, ao mesmo tempo em que torna a nota desnecessária, traz muitos benefícios, como:

- encaminha a reflexão do aluno, ajudando-o a resolver dúvidas, a corrigir o produto, melhorando sua qualidade, e a orientar seus próximos passos, a fim de que gerencie a própria aprendizagem;

- ajuda o aluno a expor seus medos e fantasias.

Mas nem sempre é possível realizar esse diálogo individualmente, e aí variam as estratégias dos professores: como não tenho tempo de conversar em sala, escrevo bilhetes; converso por meio deles, estabeleço um diálogo, a que os alunos respondem por escrito (P11-17.1).

É importante refletirmos um pouco mais sobre as possibilidades de se realizarem essas práticas tidas como avançadas, uma vez que os avanços dependem das condições.

Fazer anotações nas produções dos alunos de modo que eles reflitam sobre seus erros e dificuldades não é tarefa simples nem rápida de realizar. O professor P11, por exemplo, indicou que tinha dificuldades de estabelecer um diálogo com os alunos, durante a aula, o que o levava a escrever bilhetes, ainda que tivesse apenas 12 alunos sob sua responsabilidade, na semana. Ora, quem poderá exigir de um professor que tenha várias turmas com trinta a cinqüenta alunos em cada uma a realização de um procedimento tão árduo como esse?

Ainda que se reconheça o valor dessa prática, é preciso que o professor não se aventure, se não tiver condições de realizá-la a contento, pois pode desgastar-se e não conseguir, muitas vezes, o resultado esperado depois de tanto esforço. Em situações como essas, é necessário dialogar com um orientador experiente que alerte para as dificuldades de certas idéias. Contudo, também não podemos nos acomodar na dura realidade de cada um. É preciso buscar meios alternativos de realizar boas provas devolutivas para os alunos, de modo que possam usufruir dos benefícios de tal prática. 


\section{OUTRAS PRÁTICAS AVALIATIVAS}

Complementando essas práticas avaliativas gerais, manifestadas nas falas dos sujeitos da pesquisa, alguns deles contemplam outras práticas, tais como:

- a investigação das concepções dos alunos

Pergunto-me: o que ele quis dizer quando escreveu isso? Qual a forma de pensar da cabeça dele? Como será que preciso intervir para o aluno melhorar? (P2-6.4)

- a avaliação pelos pares² (os colegas)

Os alunos corrigem, entre si, suas produções, apontando falhas, e, baseando-se em critérios explícitos, levam e recorrigem. (P2-8.5)

Uso uma dinâmica em que a classe faz comentários ao trabalho de um dos alunos. (P12-16.7)

- autocorreção

O aluno, com base em fichas, avalia e revisa sua própria produção, sem passar pelo professor. (P2-8.6)

- auto-avaliação

Exijo que os alunos se observem durante sua produção (aprendizado, leitura, escrita) e me relatem suas preocupações em cada um desses aspectos. (P1117.2)

Uma prática comum é que, depois de elaborar um trabalho, eu o corrija, os alunos se auto-avaliem e os colegas avaliem os trabalhos uns dos outros. (P125.7)

- não dar notas nas produções ou não dar certo e errado

Não dou mais notas nas produções dos alunos. Dentro da concepção de avaliação formativa, o que é importante é o aluno receber uma análise de sua produção que lhe diga o que está dominado e o que não, e o que é que precisa ser melhorado. (P2-11.2)

Minha correção não é resolutiva, para que o aluno tenha a oportunidade de trabalhar sobre seus erros. Ela indica que o aluno precisa refletir sobre o erro. (P3-12.1 e 31.2)

2 Do Inglês peer-evaluation. 
- uso de planilhas de dificuldades individuais ou mesmo de observação do trabalho de classe

- preparação de atividades para evidenciar dificuldades

\section{COMO SE TRABALHA A RECUPERAÇÃO DO ALUNO}

O tema da recuperação está sempre presente no discurso educativo, ainda que não fique suficientemente claro no discurso das escolas se o que praticam é dar meios para o aluno recuperar as notas abaixo da média ou é criar condições para auxiliar o aluno no aprendizado daquilo que ele não aprendeu no tempo estipulado.

Mesmo que o discurso oficial da LDB fale em recuperação contínua ou paralela, no que ela consiste fica a critério de cada escola.

Pelas falas dos sujeitos da pesquisa, nota-se que em suas escolas as dificuldades são as mesmas que ocorrem em outras, com pequenas variações.

Primeiramente, ainda que não demonstrem, os professores têm conhecimento da sobrecarga que é realizar uma avaliação paralela. A instauração da obrigatoriedade desse processo é entendida da seguinte forma

O que eu acho é que a grande sacanagem desta história toda é que essas... as intenções do povo que escreveu a $L D B$, falando da recuperação paralela, são as melhores possíveis, e eu acredito naquilo, só que a questão é que quando tudo isso vira institucional, principalmente em escola particular - isso, na escola pública é mais grave ainda - , a questão é: passou a ser tua função e obrigação, sem nenhum custo a mais para a escola, sem nenhum pagamento a mais para o professor, dar conta da recuperação paralela também, além do que você já dava conta. (P2-17.1)

O que se percebe é que não é fácil fazer a recuperação preconizada,

Como estamos em uma fase de transição, na reforma educativa, faz-se a recuperação paralela como se pode. (P2-17.2)

Não há outros momentos para trabalhar as dificuldades, a não ser os próprios momentos de aula, o que é feito quando há condições. Seria necessário trabalhar em tempo integral para poder lidar com as dificuldades. (P4-4.5)

Quanto ao tempo estabelecido para a recuperação, há variações no modo de encaminhamento dessa questão entre as escolas de nossos sujeitos. Há escolas que estabelecem um período de recuperação depois das provas bimestrais ou trimestrais, além de contemplarem atividades de 
recuperação durante as atividades em sala de aula, e outras que têm horários diferenciados para a recuperação paralela ao longo do ano.

Existe, contudo, uma preocupação comum entre os professores: se a maioria dos alunos estiver com dificuldades, realiza-se um tipo de intervenção; entretanto, se o problema for apenas de alguns, são tomados outros rumos.

O problema da recuperação de dificuldades feita em grupo é que nem todos os alunos têm essas dificuldades. Assim, há que se criar mecanismos que corrijam as dificuldades, mas que considerem as diferenças de condições dos alunos. (P2-17.3)

Caso haja grande número de alunos com certa dificuldade, retoma-se esse conteúdo, com nova estratégia. Caso sejam poucos, são convocados para plantões. (P8-10.1)

A escola alterna a recuperação mensal que faz das matérias. Os alunos que mais precisam são convocados. Se o problema é geral, retoma-se com a classe. (P9-3.2)

Se o número de alunos com dificuldade é pequeno, retrabalham-se dificuldades específicas a partir da realização de atividades diferenciadas. (P1-3.1 e 3.2)

Quando a recuperação é individual, costumo conversar com o aluno fora do horário. Proponho atividades sobre tudo o que foi trabalhado, com roteiro diário de tarefas para cumprir e entregar. Ao longo de vinte dias desse trabalho, o aluno deve apresentar produções parciais. (P1-4.1)

A recuperação não é sobre tudo o que foi trabalhado; busco a dificuldade real do aluno. (P1-4.3)

Quanto à estrutura fora do horário normal,

Para o aluno com insatisfatório, ele é encaminhado para trabalhar durante o bimestre em atividades paralelas. (P3-9.2)

A recuperação paralela é feita com no máximo 10 alunos, semanalmente, com 2 horas de duração. (P3-8.1)

A escola tem recuperação, oficinas, plantões de dúvidas. (P7-6.1)

E aqueles alunos que têm dificuldades de aprendizagem que vão além das possibilidades de ação do professor ou da coordenação?

Quando não é possível ajudar um aluno com diferentes estratégias, ele é encaminhado para receber alguma ajuda externa. (P10-5.4.c)

Essa clareza sobre as limitações do próprio trabalho é muito importante, porque auxilia na tomada de decisões adequadas para a resolução dos problemas que surgem. Algumas vezes, porém, elas deixam 
de procurar auxílio de outros profissionais, prejudicando, no final das contas, o próprio aluno, em razão de discursos externos à escola, que propõem que todas as dificuldades que o aluno apresentar na escola devem ser resolvidos por ela.

O ideal seria que a escola tivesse condições de resolver os problemas dos alunos. No entanto, como a realidade de muitas escolas não é essa, e enquanto não se tomam medidas para que isso aconteça, o melhor, mesmo, é ter o bom senso de buscar auxílio externo para resolver os problemas existentes.

Finalizando a análise das práticas avaliativas dos sujeitos da pesquisa, vemos que a prova continua a ter papel de destaque, quer como símbolo de exigência, quer como símbolo de justiça ou de imparcialidade, uma vez que mesmo ao final da recuperação ela pode estar presente como exigência institucional

\section{A última ação de uma recuperação é uma prova. (P1-4.2)}

Pode ser feita uma prova final na recuperação; contudo, sempre há o acompanhamento de cada aluno (como foi sua participação e como esteve seu entendimento), perguntando-se a ele sobre suas percepções, inclusive. (P9-11.1)

\section{A PESQUISA E OS PRIMEIROS RESULTADOS}

Os dados da pesquisa revelaram que a experiência profissional dos professores entrevistados foi a responsável pelos conhecimentos que adquiriram e por seu aprofundamento, suprindo a formação inicial deficiente em relação aos aspectos teórico-práticos da avaliação pedagógica.

Identificamos nas falas dos sujeitos três fatores que contribuíram para o aprendizado das questões relativas ao encaminhamento da prática avaliativa:

1) a mudança, no entendimento da prática de ser professor, em função de determinadas vivências;

2) a formação na própria escola;

3) a reflexão sobre os meios necessários e disponíveis para a formação.

O primeiro deles diz respeito ao que o sujeito possa ter vivenciado, que tenha modificado a compreensão de alguma prática, seja pedagógica, seja avaliativa. 
Tendo em vista que a formação inicial foi deficiente, como já vimos, e que os sujeitos podem ter vivido em um ambiente universitário com uma visão idealizada do trabalho docente ( $N a$ faculdade, a idéia básica que corria era a de que depois de dar um ano de aulas para uma série, já se saberia para o resto da vida como dar aula para essa série. P11-30.1), o enfrentamento da realidade, com disposição reflexiva e desejo de aprender, acaba por ser uma verdadeira escola.

Nessa situação de experimentação, de caráter mais individual, é possível aprender por tentativa e erro, reforçando-se também o próprio desejo de crescer: Essa experimentação propiciou reflexão e desejo de modificações (P1-7.3)

O que modificou também a compreensão da prática, além da experimentação, foi a observação do processo de aprendizagem dos alunos e do enfrentamento de suas dificuldades, o que levou à percepção da necessidade de aprender algo mais, ou de investigar um pouco mais, para que o trabalho fosse mais bem realizado.

$\mathrm{O}$ segundo fator de aprendizagem dos sujeitos em relação aos aspectos teórico-práticos da avaliação pedagógica diz respeito às atividades em grupo desenvolvidas na própria escola.

Como vimos anteriormente, o posicionamento das escolas sobre a avaliação é bastante diversificado, o que leva alguns professores a terem clareza a respeito dos rumos a seguir - ou, ao menos, sobre os limites para suas ações -, enquanto outros não sabem que caminho tomar.

No entanto, as escolas, mesmo as que ainda não definiram um rumo claro, preocupam-se com a aprendizagem de seus professores e a troca de informações pedagógicas entre eles para que haja coerência nas suas ações:

O ambiente da escola entre professores é o do estudo, da troca, da divulgação das coisas interessantes, é um ambiente de cultura, de circulação informal de idéias. (P1-11.1 e 11.2)

Depois de entrar na escola em que está é que começou a entender a idéia do processo de aprendizagem e do crescimento. (P11-28.2)

Essas escolas se responsabilizaram pela formação continuada dos professores, ministrando, algumas vezes, cursos internos:

A escola, internamente, durante um ano, estruturou o estudo conjunto do tema avaliação. (P3-25.1)

$\mathrm{Na}$ escola em que está, estudou-se por quase um ano a prova operatória, intensamente. (P8-14.4) 
A escola tem um centro de estudos pedagógicos muito ativo, que já propiciou a vinda de um pesquisador estrangeiro, que discutiu com os professores sobre suas práticas e deu assessoria à escola; depois, continuaram a discutir as idéias desse autor e sua aplicação. (P9-20.1)

Além disso, é comum reunir os professores periodicamente, com a coordenação pedagógica ou de área, quando existem esses quadros na instituição. Podemos considerar essas reuniões uma boa medida para a formação de uma equipe de professores, porque se constituem em ponto de encontro para a troca de idéias, entre professores e coordenação. Ocorre que às vezes as reuniões não são pensadas de modo a fomentar reflexão e interlocução sobre temas importantes, levando muitas vezes os professores a questionar a necessidade de sua existência, ou a sua periodicidade tão freqüente. A esse respeito, dois dos sujeitos - P7 e P4 - manifestaram aspectos negativos desses encontros em suas escolas: o primeiro mencionou a formalidade dos encontros, e o segundo apontou que a reunião não era espaço de diálogo, mas, algumas vezes, de enfrentamento, e até de ouvir críticas não construtivas sobre o próprio trabalho.

Nessas situações de pouca clareza sobre o aproveitamento adequado das reuniões, parece haver falta de liderança da coordenação, ou mesmo desconhecimento de estratégias para orientar o grupo de professores. Entretanto, o trabalho da coordenação pedagógica é reconhecido como importante, pois auxilia na reflexão e discussão da própria prática, uma vez que os orientadores estão disponíveis para esclarecer, sugerir mudanças e o que for preciso para que o professor se sinta amparado nos caminhos que lhe são propostos.

O trabalho com uma orientadora é bom, ajudando a criar outros caminhos, porque ela está fora da situação, podendo ver as ocorrências de um outro modo, tem muita leitura e está na sala de aula também. Essa presença permite compartilhar os problemas e experimentar algumas idéias, mas com assessoria. (P2-23.4)

A existência de coordenação ajudou a entender as discussões que ocorriam na escola; e a indicação de leituras, além de constantes incentivos e do ambiente escolar, foram dando condições de se posicionar e de compartilhar suas visões. (P12-30.3)

Podemos perceber que essas instituições estimulam também a formação de grupos de professores, o que tem impacto geral na formação:

Por dois anos, discussões com os colegas, na escola, é que orientaram o que fazer e como estabelecer o novo. (P5-8.2) 
As discussões com os colegas são boas, porque você vê como pensa o outro, reflete diante do outro sobre como você faz as coisas, muda sua prática a partir da prática do outro; tudo isso vale a pena. (P9-19.4)

Com a formação desses grupos também é possível discutir o sentido da avaliação, seus objetivos na escola e o uso de diferentes tipos de instrumentos:

Em grupo é que se discute o que se estamos fazendo, o que queremos com a avaliação, para que ela serve. (P5-8.1)

Em reuniões de professores, trocamos idéias para afinar os instrumentos de avaliação e os conceitos sobre a mesma; lê-se um texto e discute-se o que cada um faz, por que faz, como faz. Sempre há uma busca de afinamento. (P11-26.1)

A escola tem adotado a seguinte sistemática: os professores trocam suas planilhas, discutindo também o que privilegiaram nas avaliações que fizeram, além de outros tópicos relacionados à prática avaliativa. (P9-19.1 e 19.2)

A existência desses grupos, porém, não é condição suficiente para a aprendizagem individual e a manutenção de uma coerência global. Há limitações:

A ajuda que os demais professores podem prestar não é algo absoluto, porque depende do nível em que estão. Já foi ajudado fortemente pelos comentários dos demais. (P6-23.1)

Para o trabalho em conjunto ser bom, é preciso que exista o hábito de se trabalhar assim, que se crie um ambiente bom, que as pessoas estejam dispostas a se expor e a trocar, e a produzir algo em conjunto. É importante também que o grupo permaneça um tempo maior como tal, porque, assim, é possivel a transformação. (P6-24.1)

O medo de errar, de se expor, de não estar à altura é que impede de se formar um grupo. (P6-25.1)

Completando as informações sobre os percursos da aprendizagem mais elaborada da tarefa avaliativa, os professores indicam o papel da leitura, isto é, do estudo, da participação em cursos e congressos, da reflexão permanente que se deve ter sobre a vida, sobre as disposições internas e sobre a profissão, para que possam crescer pessoal e profissionalmente.

É necessário criar o hábito da leitura de livros teóricos e de divulgação, para estar ciente das idéias que estão sustentando a reforma educativa - teorias vindas do exterior têm feito a escola modificar as práticas em seu interior (P12-1.2) - e fundamentar-se para mudar a perspectiva da 
avaliação, ainda que alguns livros dos medalhões da moda... são penosíssimos de ler; parecem estar distantes de nossas necessidades (P5-7.1). A ampliação das leituras fez perceber que a questão não é mais a avaliação, mas o currículo, a inserção da avaliação no projeto pedagógico, desvelar o que se deseja no percurso do aluno (P1-11.3).

A freqüência a cursos faz parte da rotina dos sujeitos da pesquisa. Tem-se a opinião de que é sempre bom ouvir os outros, porque nos põem a pensar e podem trazer algo de novo que seja bom (P1-13.1), mas a ida a cursos é só um alimento; a reflexão sobre a prática deve ocorrer na escola (P1-13.2.b). Em algumas dessas escolas, os professores assistem a muitos cursos juntos e se baseiam neles para intensas discussões e trocas de idéias (P12-30.5)

Quanto ao tipo de reflexão que se deve fomentar:

É preciso pensar na própria experiência e se o que serviu ao outro pode me servir também. (P1-13.8)

É preciso ler alguns livros, importantíssimos; e é preciso fundamentar-se para mudar a perspectiva da avaliação. (P12-31.1)

É importante lembrar de como eram feitas avaliações em nosso período escolar, e o que achávamos delas. A partir daí, ver para que servem, o que se quer com elas. (P6-30.1)

O professor precisa refletir, em primeiro lugar, o que é a avaliação para si; quando avalia, para que avalia; que instrumentos usa, em que momento são usados, o que faz ao avaliar. (P9-27.1)

É preciso compartilhar, conversar para se ajudar, compreender as fragilidades do professor. A partir dessas discussões, buscam-se as construções teóricas que ajudem a responder a alguma questão que se tenha. (P5-8.2)

Nesse movimento de aprender continuamente, é preciso ter presente que as visões e as ações modificam-se com a prática. Reformula-se o que se faz, porque se amadurece e porque as turmas se sucedem (P10-2.1), ou seja, vaise aprendendo de ano para ano, de situação para situação (P9-1.1).

Uma reflexão importante a fazer diz respeito a como vincular a teoria à prática, porque é fácil concordar com uma proposta apresentada teoricamente. O que se deve fazer em seguida é perguntar-se como isso se faz em sala de aula; como se transforma isso em instrumento; como se constrói o que foi proposto (P12-23.2).

Por fim, os conhecimentos aumentam quando se está disposto a conhecer mais de um assunto, a investigar mais, a continuar a aprender, e até a aprender juntos, no fazer! (P11-21.11). Para tanto, o professor tem de pensar em sua própria formação, à qual deve dedicar um tempo bastante grande (P12-16.5), mas não pode se esquecer de que se não estiver bem, com a cabeça boa, com ócio 
para ler, para ver um filme, para relaxar, ficará estressado, de mau humor, sem idéias boas para sugerir, para intervir nesse trabalho (P11-20.4).

\section{A PERCEPÇÃO DAS NECESSIDADES DO PROFESSOR}

Para que possamos analisar melhor as necessidades dos sujeitos da pesquisa, agrupamos suas falas do seguinte modo:

- questões de técnicas avaliativas ou de mais teoria sobre avaliação

- mais conhecimento sobre aprendizagem e sobre formas de atingir as finalidades da atividade escolar

- mais tempo

- mais auxílio

- estabelecer parcerias que ajudem a refletir

- conhecer mais

- adequar-se à realidade

Com referência às questões de técnicas avaliativas, podemos observar que alguns professores têm dificuldade em lidar com a síntese dos vários dados que foram acumulando ao longo do trabalho pedagógico em classe, sejam eles apresentados com conceitos ou com números, enquanto outros manifestam interesse em conhecer mais sobre questões técnicas ou sobre avaliação, sem maiores precisões.

Os professores percebem também a importância da elaboração de instrumentos de modo que os alunos demonstrem melhor seus conhecimentos e suas dificuldades. Algo importante que devem perceber é que exista uma relação estreita entre o trabalho em sala e a avaliação que será realizada, porque a avaliação não pode mais ser apresentada como uma ação à parte, como um fim em si mesma. Ela deve auxiliar na identificação de dificuldades e na proposição de novos caminhos para a ação pedagógica. Sabe-se que não está nela a solução dos problemas de aprendizagem dos alunos, mas por meio dela é possível identificar boa parte do que não vai bem no processo ensino-aprendizagem.

É interessante perceber nos sujeitos que a maioria das necessidades que manifestaram está vinculada à obtenção de mais conhecimento sobre aprendizagem. Isso mostra que esses professores começaram a compreender que o que importa realmente é atingir as finalidades da educação, e que para isso é necessário muito mais conhecimento do que aquele obtido no início da própria formação. 
Sem entender como as pessoas aprendem e como é possível ajudálas a realizar a aprendizagem, todo o trabalho docente não chega a seu termo. É provável que um melhor entendimento da avaliação, nas perspectivas do auxílio, da compreensão do outro, tenha ajudado os professores a perceberem a importância da aprendizagem, pois é no enfrentamento da elaboração dos instrumentos a serem usados na aula ou em provas, na perspectiva de melhorar o que está sendo avaliado, que nos damos conta da importância ou não do que se está ensinando, e das dificuldades em definir exatamente o que se quer como resposta.

Quanto às necessidades de mais tempo e mais auxílio para a realização da tarefa avaliativa, são plenamente compreensíveis, porque a avaliação não é custosa apenas na sua preparação, mas também na gestão de seus desdobramentos - a produção do aluno sobre as devolutivas, a recuperação daqueles que precisam, a burocracia etc. Portanto, é necessário mais auxílio para poder ajudar os alunos com dificuldades, e também para que o professor tenha mais respaldo e com quem compartilhar suas inquietações e dificuldades.

Na perspectiva da formação continuada e da criação de um bom ambiente de trabalho, vemos que há a preocupação por estabelecer parcerias que ajudem a refletir, o que é muito importante, se o que se quer é um trabalho centrado em um projeto pedagógico de escola em que todos possam contribuir para o bem comum.

Para finalizar, temos de enfatizar o pensamento de alguns professores quanto à importância da adequação das próprias concepções e do trabalho à realidade, para que o professor não se sinta o todo poderoso, que sabe tudo sobre os alunos, ou mesmo que tem condições de interferir nas carências verificadas na avaliação que realiza. Nesse sentido, é bom que existam pessoas que representem a instituição e que saibam o que representa adequar-se ao real, para poder instruir e aconselhar aqueles professores - que sempre existem - que imaginam poder fazer tudo. Nesse momento, é muito importante uma orientação segura para que o professor não se desgaste, pensando que está fazendo o melhor para seus alunos. Certamente, é fundamental não se deixar mediocrizar, buscando modificar o que não está bom; no entanto, é preciso não passar da conta para não se desgastar. 


\section{CONCLUSÕES}

Primeiramente, é necessário percebermos que todos os entrevistados se preocuparam com a qualidade da aprendizagem de seus alunos. Essa preocupação levou-os, em grupo, em suas escolas - muitas vezes influenciados pela instituição -, ou sozinhos, a buscarem informações sobre como realizar mudanças nas suas práticas didáticas. E foi interessante observar esse movimento, uma vez que nossa experiência - de quase 15 anos de magistério - mostra-nos que muitos deles, quando notam deficiências no que fazem, em vez de buscarem compreender os motivos de suas ações ou um entendimento mais amplo do que ocorre na educação, imputam essas dificuldades, ingenuamente, às características da nova geração de alunos, à falta de vontade de aprenderem, à não participação da família etc.

Pois bem, essa preocupação com as mudanças tem redundado em um movimento pessoal com diferentes características:

- para alguns sujeitos, cujas escolas têm um linha pedagógica bem estabelecida, bastante divulgada entre os professores e continuamente discutida, a busca de novas formas de ação parece ser realizada de dois modos: um baseado na coletividade de professores, em um processo conduzido pela própria escola, e outro apoiado na própria condição pessoal (interesses, desejos, motivação) de busca de novos caminhos para atuar;

- para outros sujeitos, cujas escolas não têm tradição em fomentar espaços de discussão, diálogo, reflexão coletiva (algumas delas estão buscando desenvolver essas qualidades, enquanto outras apenas acreditam possuir essas características), os custos da mudança parecem altos, porque não conseguem interlocução; há escasso acesso a material interessante e bem-estruturado que indique o "caminho das pedras" (mesmo que seja apenas para reflexão e não para receitas); falta apoio institucional concreto (o que há, na verdade, é a exigência para que se efetivem mudanças, ainda que não se indique o modo de realizá-las), e se cria uma tensão entre o desejável e o realizável, mesmo que o desejável não esteja tão claro, em razão da falta de acesso a informações seguras.

A análise dessas entrevistas leva-nos a crer na tentativa e na busca de mudanças no campo das concepções pedagógicas dos professores entrevistados, no sentido de se preocuparem em garantir a seus alunos 
sucesso real em seu desenvolvimento, ainda que poucos tenham problematizado as condições para atingir tal objetivo.

$\mathrm{Na}$ verdade, o que parece ter ocorrido foi o aumento da preocupação desses professores em organizar seu trabalho de modo a garantir a aprendizagem de seus alunos, lançando mão, muitas vezes, de estratégias de interação pessoal e grupal que fogem completamente do discurso unidirecional dos modelos mais tradicionais de ensino; ou reordenando dinamicamente sua ação didática, em função das necessidades dos alunos, o que também está bem distante das aulas preparadas "uma vez para sempre", sem considerar as interações entre o conteúdo a ser aprendido e cada grupo de alunos.

Diante desse esforço do professor, a avaliação aparece, ainda que de modo indeciso, como um meio a mais de garantir aos alunos um domínio maior daquilo que têm para aprender.

Esse modo vacilante de a avaliação se manifestar é compreensível, uma vez que não é fácil pôr em prática aquilo que não está bem explicado por seus criadores, e para o qual não se dispõem de modelos. Como afirma Zabala (1998), um conteúdo procedimental exige a apresentação de modelos magistrais, bem realizados, sobre os quais se possa observar a relação entre as partes, e as transições entre cada uma delas. Uma vez que a avaliação é um procedimento, não importando de que modelos estejamos falando, fica evidente perceber a dificuldade de internalizá-la quando os meios disponíveis para esse intento são apenas leituras ou explicações, sem observar as ações correspondentes.

A finalidade da pesquisa era compreender, por meio da fala dos professores, como as diferentes perspectivas avaliativas ou modelos avaliativos presentes na reflexão acadêmica influenciam os professores, se é que influenciam; as dificuldades que enfrentam na realização da avaliação de seus alunos; e o que pode estar impedindo as mudanças nas práticas avaliativas.

Considerando a dispersão teórica no campo da avaliação e o estado de pouca estruturação desses discursos, muitos dos quais ainda não conseguiram atingir o estágio de experimentação, em pequena escala, de suas proposições; a inexistência de um grupo de pesquisadores e práticos que reflita regularmente a respeito da avaliação educacional no âmbito da escola 3 ; a formação inicial do professor quase inexistente sobre avaliação; e poucas atividades de formação continuada acerca da temática, fica difícil acreditar na possibilidade de o professor conhecer essas diferentes abordagens teóricas sobre avaliação, e mesmo de ser influenciado por elas.

3 Ainda que contemos agora com a Associação Brasileira de Avaliação Educacional (ABAVE), que já organizou três encontros nacionais de pesquisadores. 
No entanto, fica evidente a presença, nas práticas pedagógicas dos sujeitos de nossa pesquisa, de algumas preocupações com relação a certas práticas e das intenções associadas aos discursos cujo foco é o desenvolvimento da avaliação formativa, como o Mastery Learning (Bloom, 1971), o Ensino Diferenciado, a Avaliação para a Aprendizagem. Qual seria a origem dessa "contaminação"?

Seguramente a origem está na divulgação das obras de Philippe Perrenoud entre nós, e mesmo na sua presença em diferentes encontros e congressos de educação nos últimos anos, porque o Mastery Learning não teve essa acolhida, ainda que algumas obras desse autor, vinculadas à temática, tenham sido traduzidas para o português, mormente nas décadas de 1970 e 1980. Já a contribuição da escola inglesa-escocesa-irlandesa é muito pouco divulgada entre nossos pesquisadores, quem dirá entre os professores do Ensino Básico.

Considerando a segunda pergunta da pesquisa - "as dificuldades que os professores enfrentam na realização da avaliação de seus alunos" pudemos ver, pela análise dos dados, que muitas são as dificuldades, passando pela falta de tempo e de conhecimento para elaboração de instrumentos ou de materiais que sejam capazes de medir o nível de conhecimento dos alunos e suas dificuldades; as incompreensões que vêm de todos os lados: dos alunos, das famílias, dos colegas de trabalho, da coordenação, e mesmo da direção; o volume de trabalho, que inviabiliza maior aproximação do professor com os alunos que têm mais necessidades; e desconhecimentos de várias ordens sobre aspectos teóricos e práticos da avaliação que auxiliem o trabalho de melhorar a aprendizagem dos alunos.

Estreitamente relacionada a essas dificuldades, impedindo mudanças nas práticas, estão as condições de trabalho - não problematizadas pelos inúmeros autores que propõem os mais diferentes modelos avaliativos -; a formação inicial ainda inexistente; a falta de atividades de formação continuada que dêem sustentação e suscitem novas atitudes profissionais; a dispersão de abordagens teóricas - sem material que coteje suas perspectivas, intenções, condições e implicações para a prática pedagógica geral do professor etc. - e a falta de material de base que concretize todas as idéias dos diferentes discursos avaliativos. Com respeito a este último ponto, é esclarecedor o ensinamento de Gatti (2000):

[...] em Educação, temos boa bibliografia crítica, pesquisas, artigos de debates, mas pequeno acervo bibliográfico, no mais das vezes desatualizado, sobre questões ligadas diretamente às aprendizagens básicas necessárias ao exercício da profissão propriamente dita: os "quê", os "como" e os "porquê" fazer e "quando" fazer. Apenas desenvolver a crítica não basta para ninguém, pois esta acaba sendo estéril $e$ vazia de referenciais concretos. É preciso, com sabedoria, aliar aquilo que é 
necessário saber para saber fazer, com o que é necessário saber para analisar, refletir e criticar para transformar. (p.40)

$\mathrm{Ou}$ seja, de pouco adiantará continuarmos produzindo tantos escritos acadêmicos sobre avaliação, se não fizermos esforços para concretizar todas essas idéias de modo claro, preciso e que orientem a tomada de posição do professor.

Mas voltemos um pouco à questão da formação.

Apesar de se referirem apenas a doze sujeitos, os dados apresentados são simplesmente a "ponta do iceberg" do descuido com a formação inicial dos professores nas licenciaturas, ao menos com respeito à avaliação. Para vislumbrar-lhe a extensão, basta observar a dispersão dos dados em relação ao tempo de magistério de cada um dos professores: 7 , $10,11,15,18,20,20,25,26,26,27$ e 27; ou seja, com base em um pensamento ingênuo, ao menos os grupos que se formaram com esses professores, nas respectivas faculdades, é que não tiveram a oportunidade de refletir sobre a avaliação pedagógica. E os demais professores?

Apenas para ilustrar a situação atual da formação inicial, restringimo-nos a duas universidades paulistas com tradição na formação de professores. Na PUCSP, no currículo de Pedagogia, há apenas um semestre de curso sobre avaliação e medidas educacionais, mas nenhuma disciplina com esse conteúdo no currículo das licenciaturas; e a USP, tanto no currículo das licenciaturas quanto no de Pedagogia, não oferece mais esse curso.

Esse estado de coisas é realmente intrigante, considerando-se que a avaliação está presente em todas as disciplinas e atividades escolares e tem grande peso nos percursos de toda e qualquer pessoa.

Na ausência de formação específica para a tarefa avaliativa, ou para o entendimento de sua importância no processo ensino-aprendizagem, na formação inicial dos professores, o próprio senso comum indica que haverá problemas para realizá-la.

Diante dessa carência em sua formação, muitas vezes nem sentida, mas tendo necessidade de avaliar seus alunos, em que os professores amparam, fundamentam sua prática? Sem dúvida, nas vivências escolares, nas quais, por doze anos seguramente (período escolar) mais os anos de universidade, experimentaram o próprio processo avaliativo (cognição, afetos e sentimentos).

$\mathrm{Na}$ verdade, não se trata de uma cópia pura e simples de um modelo, uma vez que cada professor lembra, ao menos, a forma de trabalho de seus professores da faculdade e do ensino médio, podendo, assim, fazer uma mescla de vários estilos, ou seguir, pelo menos, o modo de trabalhar dos professores da disciplina que leciona. 
Em razão do que foi visto, o que fazer para iluminar a questão da formação para a avaliação educacional em sala de aula?

O ideal seria que os professores, tendo por base sua própria trajetória pessoal e profissional e as possibilidades de formação no próprio espaço escolar, pudessem conhecer aspectos teóricos importantes, que os ajudaria a refletir sobre as próprias práticas, para repensá-las e verificar se estão adequadas às expectativas profissionais. E os pesquisadores que têm essa preocupação deveriam ater-se mais à realidade da sala de aula. Com isso, poderiam contribuir não somente com descrições e análises dos problemas da avaliação realizada nesse espaço - muitas vezes apenas como exercício intelectual-retórico-acadêmico do uso adequado de conceitos e formas de refletir de quadros teóricos particulares -, mas também com propostas concretas e reflexões que orientem a formação continuada de professores sobre o tema.

Diante das diferentes abordagens teóricas sobre a avaliação, um caminho para ajudar os professores a se apropriar de algumas delas seria fazer o que propõem Vianna (2000), Bonniol e Vial (2001), e Stufflebeam (2001), ou seja, apresentar a eles as diversas abordagens, mostrando suas inter-relações e possibilitando o conhecimento de determinados aspectos da avaliação tradicional - teoria da medida e outras questões psicométricas - porque sua prática, afinal de contas, contempla algumas estratégias que estão presentes nessa abordagem, muitas vezes denominada, não sem um certo ranço, de tecnicista.

Contudo, cabe apresentar todos esses conhecimentos de um modo que considere que os professores são adultos, que têm experiências e necessidades, e aprendem de determinadas formas, como indicam algumas pesquisas sobre formação de professores. Outrossim, devemos considerar a múltipla natureza dos conteúdos de aprendizagem tal como nos apresentam Zabala (1998) e Coll et al. $(1997,1998)$.

Tendo em vista que a avaliação é um processo, mas que contempla certos aspectos conceituais e muitos atitudinais, será importantíssimo para a formação do professor levar em conta todos esses fatores.

\section{REFERÊNCIAS BIBLIOGRÁFICAS}

BLACK, Paul; WILIAM, Dylan. Inside the black box: Raising standards through classroom assessment. London: King's College, 1998. 
BLOOM, B. S. Mastery Learning. In: BLOCK, J. H. (ed.) Mastery Learning: theory and practice. New York: Holt, Rinehart and Winston, 1971, p. 47-63.

BONNIOL, Jean-Jacques; VIAL. Michel. Modelos de avaliação: textos fundamentais. Porto Alegre: ArtMed, 2001.

BRZEZINSKI, Iria; GARRIDO, Elsa. O que revelam os trabalhos do GT Formação de Professores. In: ANDRÉ, Marli E. D. A. (org.). Formação de Professores no Brasil (1990-1998). Brasília: MEC/Inep/Comped, 2002.

COLL, Cesar et al. O construtivismo em sala de aula. São Paulo: Editora Ática, 1997.

Os conteúdos na reforma: ensino e aprendizagem de conceitos, procedimentos e atitudes. Porto Alegre: ArtMed, 1998.

DE KETELE, Jean-Marie. L'évaluation conjuguée en paradigmes. Revue Française de Pédagogie, n.103, avril-mai-juin, 1993, p.59-80.

GATTI, Bernardete A. Formação de professores e carreira: problemas e movimentos de renovação. 2. ed. Campinas, SP: Autores Associados, 2000.

Formação plena para os professores. Fundação Carlos Chagas, Difusão de Idéias, dez. 2006.

GUBA, Egon G.; LINCOLN, Yvonna S. Fourth Generation Evaluation. Thousand Oaks, London and New Delhi: Sage, 1989.

RONCA, P. A. F.; TERZI, C. A. A Prova operatória. São Paulo: Instituto Esplan, 1991.

ROJAS, Hugo de los Santos. A Avaliação em sala de aula: quais as dificuldades para a formação do professor do ensino básico? São Paulo, 2007. Dissertação (mestr.) Pontifícia Universidade Católica de São Paulo.

STUFFLEBEAM, Daniel L. Evaluation Models. New Directions for Evaluation, n.89, spring 2001. San Francisco: Jossey-Bass.

VIANNA, Heraldo M. Avaliação educacional: teoria, planejamento, modelos. São Paulo: Ibrasa, 2000. 
WILIAM, Dylan. Enculturating learners into communities of practice: raising achievement through classroom assessment. Paper presented at the European Conference for Educational Research, University of Ljubljana, Slovenia, September 17th to $20^{\text {th }}, 1998$.

ZABALA, Antoni. A Prática educativa: como ensinar. Porto Alegre: ArtMed, 1998.

Recebido em: dezembro 2006

Aprovado para publicação em: março 2007 